\title{
CATAMNESTIC OBSERVATION OF CARDIOVASCULAR STATUS IN PRETERM INFANTS
}

\author{
Gonchar M., Boichenko A. \\ Kharkiv National Medical University, Kharkiv, Ukraine
}

\begin{abstract}
To identify peculiarities of the diastolic function development of the heart ventricles in preterm infants following clinical and instrumental examination in the neonatal period and in the process of catamnestic observation the study involved examination of 244 preterm infants at gestation age from $26^{0-7}$ to $37^{6-7}$ weeks. Control group comprised 100 healthy full-term infants. The study showed that peculiarities of the development of diastolic function of the heart ventricles in prematurely born children included diastolic dysfunction by the type of delayed relaxation, which is typical for the fetus, until the child reaches the postconceptual age of 39-41 weeks. Normalization of the diastolic function of the heart ventricles occured in $46 / 61\left(75.41 \pm 5.51 \%, \mathrm{p}=0.1 \cdot 10^{-6}\right)$ prematurely born children to 5-6 months of actual age, in 15/61 (24.59 $\pm 5.51 \%$ ) children to 6-8 months of actual age. Spontaneous closure of open oval window up to the age of 1 year occurred in 22/32 $(68.75 \pm 8.19 \%, \mathrm{p}=0.009)$ full-term newborns and in 21/61 (34.43 $\pm 6.08 \%$ ) preterm infants. Hemodynamically significant patent arterial duct in $58.82 \pm 11.94 \%$ of children spontaneously closes during the first three months of life. The incidence of myocardial dysfunction in newborns from mothers with extragenital pathology increased to $89.39 \pm 3.79 \%$ versus $76.67 \pm 5.46 \%, p=0.046$ children born from healthy women. The presence of extragenital pathology in mothers, including cardiovascular disorders, is a risk factor for the development of cardiovascular diseases in preterm children.
\end{abstract}

Key words: preterm infants, myocardial dysfunction, catamnesis.

The transition from fetal to extrauterine life is the most complex physiological process of adaptation of the newborn. The beginning of independent breathing results in radical changes not only in the respiratory tract, but also in the cardiovascular system [1], which is associated with changes in pressure in heart chambers, the direction of blood flow on the level of fetal communication, as well as in remodeling of heart chambers and great vessels due to changes in hemodynamic load. Preterm labor causes difficulties in adaptation of premature infants [1], triggering a delay in neonatal remodeling of intracardiac and systemic hemodynamics. An instance of blood circulation adaptation impairment after birth is persistent pulmonary hypertension [2]. Issues of the development of

Corresponding Author:

Alena Boichenko, MD, PhD, Associate Professor of Pediatrics 1 and Neonatology Department of Kharkiv National Medical University, Ukraine. E-mail: adboichenko@gmail.com diastolic function of heart ventricles and interpretation of the rate and time parameters according to echocardiography data remain urgent not only in the neonatal period $[3,4,5,6]$, but during the first year of life.

Proper assessment of hemodynamic state and detection of myocardial dysfunction in newborns enables promptly diagnose the first signs of cardiovascular involvement, even as early as at preclinical stage. Polymorphism and nonspecific clinical manifestations of cardiovascular maladaptation create certain diagnostic challenges that can only be solved with time, in the process of catamnestic observation.

The purpose of the study: to identify peculiarities of the diastolic function development of the heart ventricles in preterm infants following clinical and instrumental examination in the neonatal period and in the process of catamnestic observation.

Object and methods of the study: The study involved examination of 244 preterm infants at gestation age from $26^{0-7}$ to $37^{6-7}$ weeks. The 
newborns were divided into the following groups: Group $1(<28$ weeks - extreme degree of prematurity) $-25 / 244$ (10.25 $\pm 1.94 \%)$, Group 2 $\left(28^{0-7}-31^{6-7}\right.$ weeks - very early preterm infants) $40 / 244$ (16.39 $\pm 2.37 \%)$, Group $3\left(32^{0-7}\right.$ $33^{6-7}$ weeks - early preterm infants) $-61 / 244$ $(25.0 \pm 2.77 \%)$, Group $4\left(34^{0-7}-36^{6-7}\right.$ weeks "late preterm infants") - 118/244 (48.36 $\pm 3.2 \%)$ children. "Late preterm infants" was the most numerous group, which was associated with general statistical data [7]. Given that "late preterm infants" have a higher level of short-term morbidity compared to full-term children [8], this group was analyzed separately.

Control group included 100 healthy full-term newborns, with uneventful early neonatal period.

The study implied assessment of medical histories, clinical and laboratory-instrumental examination of children in the neonatal period and at the age of 3, 6, and 12 months of the actual age.

Doppler echocardiography (DECG) was performed using ultrasound scanner "MyLab25Gold" manufactured by "Esaote" (Italy) with determination of indices characterizing the systolic and diastolic function of the ventricles in accordance with the recommendations for neonatologist performed echocardiography in Europe: Consensus Statement endorsed by European Society for Pediatric Research (ESPR) and the European Society for Neonatology (ESN) [9].

Statistical processing of the data was carried out using SPSS Statistics 17.0 and STATISTICA10 software. Comparison of the studied groups by quantitative features was carried out using the Mann-Whitney and Student criteria. For qualitative signs, statistical significance of the differences was checked by nonparametric criteria: $\chi^{2}$, the exact Fisher criterion with calculation of the $\partial$ value. The value of $\mathrm{p}<0.05$ was taken for the threshold of statistical significance.

Results of the study and their discussion. Assessment of obstetric history showed pathological course of pregnancy (threatened abortion, placental dysfunction, antenatal distress of the fetus, premature rupture of membranes) in 68/105 (64.76 $\pm 4.66 \%, \mathrm{p}=0.00001$ ) women. Multiple pregnancy occurred in 19/105 (18.1 \pm 3.76$)$ women. Two triplets and 17 twins were born.

Extragenital pathology was found in 54/105 (51.43 $\pm 4.88 \%, \mathrm{p}=0.38)$ of women. Exacerbation of chronic pyelonephritis was observed most frequently (16/105 (15.24 $\pm 3.51 \%)$. Allergic diseases and bronchial asthma, which complicated the course of pregnancy, were diagnosed in 3/105 (2.86 \pm 1.63$)$ mothers. Gastrointestinal diseases (chronic gastritis, duodenal ulcer, chronic cholecystitis) were found in 6/105 (5.71\% $\pm 2.26 \%)$ women, endocrinepathology (primary hypothyroidism, medication compensated, obesity) in 3/105 (2.86 $\pm 1.63 \%$ ) of women. The course of pregnancy secondary to anemia of mild and moderate severity was reported in 16/105 (15.24 \pm 3.51$)$ mothers. The study showed that extragenital pathologies complicated the course of pregnancy in $40 / 55(72.73 \pm 6.01 \%, \mathrm{p}=0.036)$ women. Every fourth woman, 22/105 (20.95 $\pm 3.97 \%$ ), had compromised heredity for cardiovascular disease, and almost every fourth one 18/105 (17.14 \pm 3.68$)$ had cardiovascular pathology. More often, cardiovascular pathology was registered in mothers of newborns with extremely low birth weight $(11 / 30(36.67 \pm 8.8 \%))$ and mothers of newborns with very low birth weight (9/28 (32.14 $\left.\pm 8.83 \%, \chi^{2}=14.672, \mathrm{p}=0.001\right)$ ) compared to mothers of low birth weight children (5/68 (7.35 $\pm 3.16 \%)$.

After birth, 92/126 $\left(73.02 \pm 3.95 \%, \mathrm{p}=0.3 \cdot 10^{-11}\right)$ of preterm infants were diagnosed with infant respiratory distress syndrome (IRDS) and / or $74 / 126(58.73 \pm 4.39 \%, p=0.01)$ asphyxia at birth, with clinical and laboratory and instrumental confirmation. Besides, 43/103 (41.75 $\pm 4.86 \%)$ newborns were shown to have hypoxic-ischemic impairment of the central nervous system and 23/ $126(18.25 \pm 3.44 \%)$ of children were somatically healthy - these were children at gestation age of $32.28 \pm 0.95$ weeks.

Clinical examination of preterm children did not reveal specific signs of myocardial dysfunction. It showed microcirculatory disorders in the form of marble hue of the skin in 69/103 (66.99 \pm $4.63 \%, \mathrm{p}=0.000005$ ) newborns, perioral cyanosis in 29/103 (28.16 $\pm 4.43 \%$ ), tachypnea in 66/103 (64.08 $\pm 4.73 \%, p=0.0002)$, participation of auxiliary muscles in the act of respiration in 28/ $103(27.18 \pm 4.38 \%)$ patients. These clinical signs more often testified to the presence of respiratory disorders and microcirculatory disorders secondary to perinatal damage to the central nervous system.

Auscultation of the heart showed systolic noise in the $2^{\text {nd }}-3^{\text {rd }}$ intercostal space to the left of the sternum in 37/126 (29.37 $\pm 4.06 \%)$ preterm children which intensity depended on the presence of patent arterial duct, its diameter, as well as the time course of IRDS and the mean pressure in the pulmonary artery.

According to Leone A, Ersfeld P. et al. (2012) the "late preterm infants" are a special group for the development of medical complications at the 
stage of postpartum adaptation [8], which is important for assessing and identifying the features of hemodynamic adaptation in the neonatal period.

The study involved examination of 118/244 (48.36 $\pm 3.2 \%)$ "late preterm" newborns at gestation age from $34^{0 / 7}-36^{6 / 7}$ weeks. Multiple pregnancy was observed in 29/88 (32.95 $\pm 5.01 \%$ ) women, of whom 28/29 (96.55 $\pm 3.39 \%, \mathrm{p}=$ 0.000001 ) had twins, one woman had triplets. Pathological pregnancy occurred in 68/88 (77.27 $\pm 4.47 \%$, $\mathrm{\partial}=0,5 \cdot 10^{-11}$ ) women. Moreover, $24 / 88$ $(27.27 \pm 4.75 \%)$ of women had premature rupture of membranes and 12/88 (13.64 $\pm 3.66 \%)$ had preeclampsia. Antenatal distress and fetal development delay syndrome were recorded at the same frequency, namely 4/88 (4.55 $\pm 2.22 \%$ ) of pregnant women, and the same frequency was associated with placental dysfunction and abnormal changes in the amount of amniotic fluid (oligohydramnios, polyhydramnios) in 6/ 88 (6.82 $\pm 2.69 \%$ ). Placenta previa was observed in $4 / 88$ $(4.55 \pm 2.22 \%)$ mothers. The threat of preterm delivery was registered in 40/88 (45.45 $\pm 5.31 \%$ ) mothers.

Extragenital pathology was diagnosed in 60/ $88(68.18 \pm 4.97 \%, \mathrm{p}=0.000007)$ women. Chronic infectious pathology was the most common, namely chronic pyelonephritis in 18/88 (20.45 $\pm 4.3 \%)$ and chronic tonsillitis in 2/88 (2.27 $\pm 1.59 \%$ ); exacerbation of bronchial asthma occurred in two women. Endocrine pathology (primary medically compensated hypothyroidism, obesity) was found in 8/88 (9.09 \pm 3.06$)$ mothers. Pregnancy in patients with anemia was observed in 7/88 (7.95 $\pm 2.88 \%)$ of mothers. One woman had a past history of acute lymphoblastic leucosis. Varicose disease of the lower extremities occurred in 6/88 (6.82 $\pm 2.69 \%)$ women. Cardiovascular diseases (arterial hypertension, secondary cardiomyopathy, congenital heart defect, heart rhythm disorders and vegetative-vascular dysfunction) were observed in 25-88 (28.41 \pm $4.81 \%$ ) mothers. A statistically significant relationship was found between the presence of cardiac pathology in a mother and the presence of 27/67 (40.30 $\pm 5.99 \%, p=0.024)$ of myocardial dysfunction in a child in the early neonatal period. Each third woman (28/88 (31.82 $\pm 4.97 \%)$ ) had a comorbidity of somatic pathology, which complicated the course of pregnancy.

According to the results of the clinical and instrumental examination, 30/118 (25.42 $\pm 4.01 \%)$ of "late preterm" infants had clinical problems such as IRDS, in 21/30 (70.0 $\pm 8.37 \%, p=0.007)$, moderate degree of asphyxia during labor in $10 /$ 30 (33.33 $\pm 8.61 \%, p=0.03)$ children, and 5/30 $(16.67 \pm 6.8 \%)$ newborns had a delay in intrauterine development.

"Late preterm" infants were not found to have specific signs of cardiovascular maladaptation. The most common were clinical signs typical for IRDS and asphyxia during labor. Auscultation detected systolic noise in 109/118 (92.37 $\pm 2.44 \%$, $\mathrm{p}=0.00001)$ newborns, of whom 91/118 (77.12 $\left.\pm 3.87 \%, \mathrm{p}=0,3 \cdot 10^{-36}\right)$ in a.pulmonale due to the presence of patent arterial duct and / or minimal physiological reverse flow in the pulmonary arterial valves.

Doppler echocardiography showed that the formation of diastolic function of the heart ventricles in healthy full-term neonates occurs during the first week of life. Parameters of diastolic flow in newborns in the early neonatal period have a phase redistribution: with the prevalence of early diastolic filling and a moderate increase in the ratio of early and late transmitral flow for the left ventricle; with predominance of the atrial component for the right ventricle [4].

Myocardial dysfunction was registered in $105 / 126\left(83.33 \pm 3.32 \%, p=0.7 \cdot 10^{-24}\right)$ of preterm children. Extragenital pathology in a mother was shown to be associated with an increase in the percentage of myocardial dysfunction incidence in newborns to $89.39 \pm 3.79 \%$ versus $76.67 \pm$ $5.46 \%, \mathrm{p}=0.046$ children born from healthy women. Clinically important is the fact that the risk of developing myocardial dysfunction in children whose mother had a risk of abortion was 57/105 (54.29 $\pm 4.86 \%, p=0.01)$. Diastolic dysfunction of the heart ventricles was recorded most commonly, in 80/105 (76.19 $\pm 4.16 \%$, $\mathrm{p}=$ $\left.0.3 \cdot 10^{-12}\right)$. In $45 / 105(42.86 \pm 4.83 \%)$ of newborns, a violation of the systolic function of the right ventricle (mainly in children at gestational age from 24 to 31 weeks) was diagnosed in infants with respiratory distress, severe asphyxia during labor or prosthetic repair of external breathing function. Systolic dysfunction of the left ventricle was diagnosed in 16/105 (15.24 $\pm 3.51 \%)$ of prematurely born children.

Doppler echocardiography showed myocardial dysfunction in 67/118 (56.78 $\pm 4.56 \%$ ), "late preterm" newborns, statistically more often in in those born from mothers with extragenital pathology $\left(51 / 67\left(76.12 \pm 5.21 \%, \mathrm{p}=0.1 \cdot 10^{-7}\right)\right)$. Diastolic dysfunction was found in 63/118 (53.39 $\pm 4.59 \%)$ of the "late preterm" neonates: left ventricular in 25/63 (39.68 $\pm 6.16 \%)$ and biventricular in 38/63 (60.32 $\pm 6.16 \%)$. The left 
ventricular systolic dysfunction was detected in $12 / 118(10.17 \pm 2.78 \%)$ newborns and right ventricular in 34/118 (28.81 $\pm 4.17 \%)$.

High incidence of diastolic dysfunction can be attributed to the fact that type 1 myocardial dysfunction (delayed relaxation) is more typical for fetal heart ventricles. Its presence can be explained by the systemic intrauterine functioning of the right ventricle in the absence of a hemodynamic load on the left ventricle [10]. Our independent studies have found that a neonatal myocardium in a premature baby shows features of the diastolic function of the heart ventricles, which is typical for the fetus until postconceptual age of 39-41 weeks. In future, the diastolic function in preterm infants is normalized and does not differ from the normal values of full-term infants by the rate and time parameters.

Systolic dysfunction of the heart ventricles was detected in newborns with respiratory disorders and / or asphyxia secondary to insufficient hemodynamic adaptation of the left ventricle to the load.

After discharge from the perinatal center at the age under 12 months of the actual age, 93 children were examined, of whom 61 were preterm and 32 were healthy children of the control group. They underwent follow-up examination: in the interval of 1 month, 3, 6 and 12 months of actual age. Given the fact of premature birth, morphofunctional immaturity, the time of stabilization of diastolic function in prematurely born children and "late preterm infants" was different from that of newborn babies. Rate and time indices were found to normilize in 46/61 (75.41 $\pm 5.51 \%, p=0.1 \cdot 10-6)$ prematurely born children from 5-6 months of actual age, indicating the normalization of diastolic function, in 15 / 61 (24.59 $\pm 5.51 \%)$ children to 6-8 months of actual age.

Hemodynamically significant open arterial duct was diagnosed in 17 children with extremely low and very low birth weight. All patients in this group were found to have disturbances in the diastolic function of the left and right ventricles of the heart by the type of delayed relaxation. In $10 / 17$ (58.82 $\pm 11.94 \%)$ patients, spontaneous obliteration of the duct occurred at the end of the third month of life (from 31 to 68 days of life) with gradual normalization of the diastolic function of the ventricles in the heart at the age of 6-8 months of actual age.

Open oval window functioning was established in $100 \%$ of newborns in the neonatal period: the diameter in Group 1 children was 2.7 $\pm 0.5 \mathrm{~mm}$, Group 2 and $3-3.5 \pm 0.3 \mathrm{~mm}$, Group 4 - $3.5 \pm 0.4 \mathrm{~mm}$. Spontaneous closure of open oval window in newborn infants occurred up to 6 months of life in 10/32 (31.25 $\pm 8.19 \%)$ and $12 /$ $32(37.5 \pm 8.56 \%)$ children up to 1 year. Spontaneous closure of open oval window in prematurely born children under one year of age occurred in 21/61 (34.43 $\pm 6.08 \%)$. The study showed that the size of open oval window did not depend on gender, weight at birth, gestation period.

\section{Conclusions:}

1) The peculiarities of the development of diastolic function of the heart ventricles in prematurely born children included diastolic dysfunction by the type of delayed relaxation, which is typical for the fetus, until the child reaches the postconceptual age of 39-41 weeks.

2) Normalization of the diastolic function of the heart ventricles occurred in 46/61 (75.41 \pm $5.51 \%, \mathrm{p}=0.1 \cdot 10^{-6}$ ) prematurely born children to 5-6 months of actual age, in 15/61 (24.59 \pm $5.51 \%$ ) children to 6-8 months of actual age.

3) Spontaneous closure of open oval window up to the age of 1 year occured in 22/32 (68.75 \pm $8.19 \%, \mathrm{p}=0.009$ ) full-term newborns and in 21/ 61 (34.43 $\pm 6.08 \%)$ preterm infants.

4) Hemodynamically significant patent arterial duct in $58.82 \pm 11.94 \%$ of children spontaneously closes during the first three months of life.

5) The incidence of myocardial dysfunction in newborns from mothers with extragenital pathology increased to $89.39 \pm 3.79 \%$ versus $76.67 \pm 5.46 \%, \mathrm{p}=0.046$ children born from healthy women.

6) The presence of extragenital pathology in mothers, including cardiovascular disorders, is a risk factor for the development of cardiovascular diseases in preterm children, which requires dynamic monitoring and monitoring of hemodynamic status for timely correction of the revealed changes.

Conflict of interest. No conflict of interest.

\section{References}

1. Noah Hillman, Suhas G. Kallapur, Alan Jobe. (2012). Đhysiology of transition from intrauterine to extrauterine life. Clin Perinatol. 39(4): 769-783. doi: 10.1016/j.clp.2012.09.009.

2. Bobby Mathew, Satyan Lakshminrusimha. (2017). Persistent Pulmonary Hypertension in the Newborn. Children, 4, 63. 14 ð.; doi:10.3390/children4080063. 
3. Boichenko A.D., Senatorova A.V., Honchar M.A., Kondratova Y.Iu. (2014). Typû dyastolycheskoi dysfunktsyy zheludochkov serdtsa u novorozhdennû kh v rannyi neonatalnû i peryod. Mezhdunarodnû i zhurnal pedyatryy, akusherstva y hynekolohyy. 5(3). 10-17.

4. Boichenko A.D. (2015). Systolichna ta diastolichna funktsii miokarda u novonarodzhenykh u rannii neonatalnyi period. Aktualni pytannia pediatrii, akusherstva ta hinekolohii. 1(15). 11-13.

5. Koert De Waal, Nilkant Phad, Anil Lakkundi, Peter Tan. (2017). Post-transitional adaptation of the left heart in uncomplicated, very preterm infants. Cardiology in the Young. 27(6), 1167-1173. doi.org/ 10.1017/S1047951116002687;

6. Escourrou G., Renesme L., Zana E., Rideau A., Marcoux M.O., Lopez E., ... Flamant C. (2017). How to assess hemodynamic status in very preterm newborns in the first week of life? Journal of Perinatology, 37(9), 987-993.

7. Amir Kugelman, Andrew A. Colin. (2013). Late preterm infants: near term but still in a critical developmental time period. Pediatrics., 132(4), 741-751.

8. Leone A., Ersfeld P., Adams M., Schiffer P.M., Bucher H.U., Arlettaz R. (2012). Neonatal morbidity in singleton late preterm infants compared with full-term infants. Acta Paediatr.;101(1): e6.

9. Willem P. de Boode, Yogen Singh, Samir Gupta, Topun Austin, Kajsa Bohlin, Eugene Dempsey, Alan Groves, Beate Horsberg Eriksen, .... Afif El-Khuffash. (2016). Recommendations for neonatologist performed echocardiography in Europe: Consensus Statement endorsed by European Society for Paediatric Research (ESPR) and European Society for Neonatology (ESN). Pediatric Research. 80(4), 465-471.

10. Fàtima Crispi, Brenda Valenzuela-Alcaraz, Monica Cruz-Lemini, Eduard Gratacós. (2013). Ultrasound assessment of fetal cardiac function. Australas J Ultrasound Med. 16(4), 158-167. doi: 10.1002/ j.2205-0140.2013.tb00242.x 